\title{
Nomogram of nasal bone length at 11-14 week of gestation in Indian women and their follow up till delivery
}

\author{
Renu Prabha ${ }^{1}$, Santosh Kumar ${ }^{2}$, Manish Kumar ${ }^{3}$ \\ ${ }^{1}$ Department of Obstetrics and Gynecology, ${ }^{2}$ Department of Paediatrics, ${ }^{3}$ Department of Radiology, MGM Medical \\ College and LSK hospital, Kishanganj, Bihar, India \\ Received: 10 October 2016 \\ Accepted: 17 October 2016 \\ *Correspondence: \\ Dr. Renu Prabha, \\ E-mail: drrenuprabha@gmail.com \\ Copyright: () the author(s), publisher and licensee Medip Academy. This is an open-access article distributed under \\ the terms of the Creative Commons Attribution Non-Commercial License, which permits unrestricted non-commercial \\ use, distribution, and reproduction in any medium, provided the original work is properly cited.
}

\section{ABSTRACT}

Background: The measurement of nasal bone length (NBL) according to gestational age and setting nomogram helps to ascertain NB hypoplasia. This can be used for early detection of trisomy 21 and other chromosomal abnormalities in low risk population. The objective of the study was to obtain nomogram of fetal nasal bone length at 11-14 weeks gestation with known prognosis pregnancies.

Methods: A single centre, prospective crosses sectional study. Nasal bone length of 323 choromosomal and structural normal fetuses at 11-14 weeks gestation were measured by transabdominal ultrasonography, prospectively. The correlation between nasal bone and other biometric parameters was assessed by regression analysis and average \pm SD of nasal bone lengths were measured.

Results: Fetal NB length (NBL) was visualized and measured in 281 patients (94.29\%). Mean NB length was 3.07 $\mathrm{mm}$, ranged between $1.60 \mathrm{~mm}$ to $4.6 \mathrm{~mm}$ and SD was 0.534 . A linear growth pattern was observed between nasal bone and fetal biometric parameters. The significant correlation were found between the nasal bone and biparietal diameter $(\mathrm{BPD})[\mathrm{NBL}=2.184+0.046 \mathrm{x} \mathrm{BPD}(\mathrm{r}=0.286, \mathrm{p}$ value 0.000$)]$, femoral length $(\mathrm{FL})[\mathrm{NBL}=2.234+0.095 \times \mathrm{xL}$ $(\mathrm{r}=0.369$, p value 0.000)] and crown-rump length $(\mathrm{CRL})[\mathrm{NBL}=2.205+0.014 \times \mathrm{xRL}(\mathrm{r}=0.291, \mathrm{p}$ value 0.000$)]$. Prenasal thickness (PT) increased linearly with CRL and POG. [PT $=1.081+0.006 \times$ CRL $(r=0.16, p$ value $=0.02)$ and $\mathrm{PT}=0.430+0.08 \times$ POG $(\mathrm{r}=0.15$, p value $=0.028)]$.

Conclusions: Measurement of the nasal bone length at 11-14 weeks of gestation shows a linear growth pattern according to other biometric parameters of fetuses. Nomogram of nasal bone length was performed for early detection of trisomy 21 and other chromosomal abnormalities at low risk population.

Keywords: Nasal bone, Transabdominal ultrasonography, Nomogram

\section{INTRODUCTION}

The first trimester screening in pregnancy is very effective in diagnosing chromosomal abnormalities and assessment of nasal bone is one of the effective secondary factors. Maternal age, Nuchal translucency (NT) and free $\beta$-hCG and PAPP-A (combined test) is found to have $85-95 \%$ detection rate for fetal aneuploidy with a false-positive rate of $5 \%$ whereas combined test along with nasal bone (NB) or tricuspid flow or ductus venosus flow has detection rate of $93-96 \%$ and false positive rate of $2.5 \%$ for euploid, $60 \%$ of trisomy 21 , $53 \%$ for trisomy 18 and $45 \%$ for trisomy $13 .{ }^{1}$ Hence, NB absence or hypolplasia is a promising component of screening test. ${ }^{2}$ Ethnic differences in NB length have been reported. ${ }^{3}$ To define NB hypoplasia, nomograms are set in Caucasian, African-American, Korean and Chinese populations. $^{4-7}$

An objective approach of measurement of NB length according to gestational age and setting nomogram helps to ascertain NB hypoplasia. This can also be used for 
early detection of trisomy 21 and other chromosomal abnormalities in low risk population. Studies have shown ethnic variation in size of nasal bone, hence, nomogram for Indian fetuses is important.

\section{METHODS}

A single centre, prospective cross sectional study to establish nomogram of fetal NB from 11 to 14 week of gestation in cohort of Indian pregnant women between gestational age of 11 to 14 week visiting antenatal clinic in department of Obstetrics and Gynaecology, MGM medical college and LSK hospital, Kishanganj. Inclusion criteria for the study were pregnant women with singleton pregnancy between gestational ages 11 week to 14 week. Cases with fetal anamoly, abnormal karyotype, multiple pregnancy, intrauterine death, abnormal first and second trimester scan were excluded from the study. Informed consent was taken from all couples. In this study, 323 pregnant women carrying single viable intrauterine pregnancy between gestational ages of 11 to 14 week attending antenatal clinic at MGM medical college and LSK hospital, Kishanganj, between 01.07.2015-30.06. 2015 were recruited. Detailed clinical history was taken which included previous obstetric history and outcome and present pregnancy details. For gestational week, last menstrual period dates were taken as a base for those who have 28-32 days of menstrual period. Sonographically determined CRL was taken as a base for those if the menstrual history is uncertain or discordant. General physical and obstetric examination was done. Routine antenatal investigations were done. Patients were given date for ultrasonography examination between 11-14 weeks of gestation. Under low brightness settings, ultrasonographic assessment was done using high resolution GE logic P3 ultrasound equipment, transabdominally using curved transducer of $3.5 \mathrm{~mm} \mathrm{HZ}$ in each patient between 11-14 weeks. Sonography was done following the recommendations of Fetal Medicine Foundation as described below. Sonographic assessment included measurement of CRL, BPD, FL, apart from assessment of NB and PT. A limited anatomic survey including views of fetal brain, face, abdomen and urinary bladder was done. Each measurement was done twice and their average was taken. Patients were followed up till delivery according to routine protocol at the study center including anomaly scan at 18-20 weeks. Patients who delivered a normal neonate at term and had normal findings at the first and second trimester scans were considered for analysis.

\section{Nasal bone length measurement}

Fetuses between gestational ages of 11 to 14 weeks were grouped at intervals of one week each. Mid-sagittal view was obtained with the fetus facing towards the transducer. Image size was magnified such that the upper thorax and the fetal head occupy $75 \%$ of the image. The angle of insonation was kept 90 degrees with the longitudinal axis of the NB (i.e., the face of transducer kept parallel to the longitudinal axis of the nasal bone). The line which was at least as echogenic as the overlying skin was taken as NB (Figure 1). A third echogenic line representing the skin of tip of the nose was seen anterior to the 'equal sign' in the mid sagittal view.

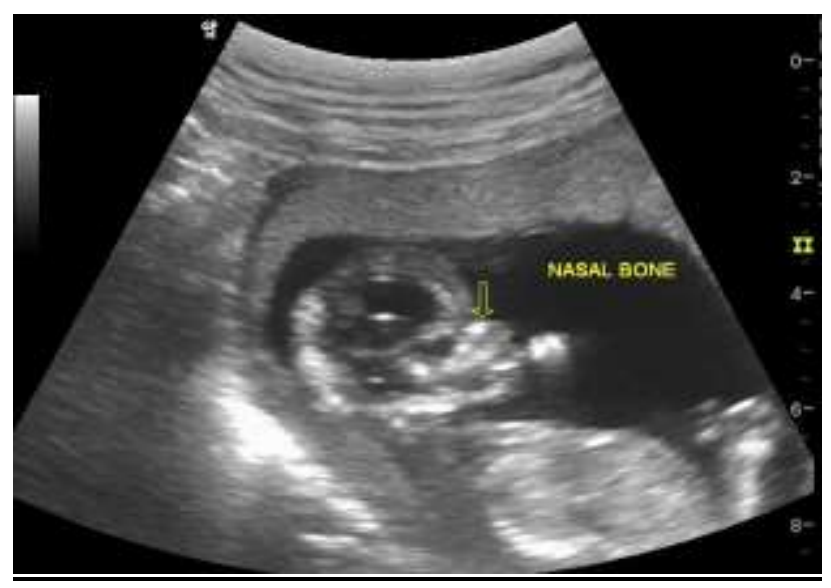

Figure 1: Nasal bone length measurement.

\section{Crown-rump length}

Mid-sagittal view of whole fetus was obtained. Embryo or fetus was adjusted in such a way that it comes in horizontal position on the screen so that the line between crown and rump is at $90^{\circ}$ to the ultrasound beam. Calipers positioned to measure the unflexed length, in which the end points of crown and rump are clearly defined.

\section{Biparietal diameter}

Measured at the plane of section through a 360 degree, that traverses the third ventricle and thalami. Focused such that calvaria are smooth and symmetric bilaterally, ensuring transducer orientation as perpendicular to the central axis of the head. Cursor is positioned from outer edge of near calvarial wall to inner edge of far calvarial wall or vice versa.

\section{Femur length}

Transducer is aligned along the long axis of the femur. Only the ossified portions of diaphysis and metaphysic are measured, excluding cartilaginous portions. The cursor is positioned at junction of bone with cartilage.

\section{Statistical analysis}

Statistical analysis was done using SPSS system (Statistical package for social sciences, Microsoft Inc, Chicago IL, USA) and ANOVA. Cases were grouped at 1 week intervals. Data on maternal age, CRL measurement were presented as medians and ranges ( $\mathrm{min}$ and max).Correlation was done using Pearson correlation. Linear regression analysis was used to analyse the relationship between the NBL and each biometric 
parameter. Stepwise regression analysis was used to analyse the relationship between the NB lengths together with other biometric parameters. $\mathrm{P}$ value $<0.05$ was considered statistically significant. Nomograms are generally made using large data sets. Since our study is preliminary, we have taken only 323 consecutive fetuses.

\section{RESULTS}

Among 323 patients recruited from July, 2015 to June, 2016, 298 patients met inclusion criteria and they included for statistical analysis. The age of pregnant women ranged from 20 to 39 years (mean, 28 years; SD, 3.98 years). The mean period of gestation at the time of sonographic evaluation was 12 week and 4 days $(\mathrm{SD}=0.77)$, ranged from 11 weeks till $13+6$ weeks. The one who had abortion; intrauterine death and fetuses above 13+6 weeks were excluded (total 25) from analysis. To set nomogram only those within 14 weeks were included. Fetal NB length (NBL) was visualized and measured in 281 patients (94.29\%). Mean NB length was $3.07 \mathrm{~mm}$, ranged between $1.60 \mathrm{~mm}$ to $4.6 \mathrm{~mm}$ and SD was 0.534 .

\section{Nasal bone and gestational age}

The nasal bone is found to increase with increasing gestational age. Majority $(45 \%)$ of NB length were measured in 12-12+6 week period. The mean NB length at 12 weeks at each week of gestation along with standard deviation is represented in the Table 1.

Table 1: Descriptive measurements of the NBL according to the gestational age.

\begin{tabular}{|lllll|}
$\begin{array}{l}\text { Gestational age } \\
\text { (weeks+ days) }\end{array}$ & n & $\begin{array}{l}\text { Mean } \\
(\mathbf{m m})\end{array}$ & SD & $\begin{array}{l}\text { Standard } \\
\text { error of } \\
\text { mean }\end{array}$ \\
\hline $11-11+6$ & 58 & 2.83 & 0.4435 & 0.0582 \\
\hline $12-12+6$ & 129 & 3.03 & 0.4795 & 0.0422 \\
\hline $13-13+6$ & 94 & 3.26 & 0.5855 & 0.0604 \\
\hline
\end{tabular}

The $50^{\text {th }}$ percentile of NB length at 11 week, 12 week, and 13 week of gestation were $2.85 \mathrm{~mm}, 3.0 \mathrm{~mm}$ and 3.2 $\mathrm{mm}$ respectively. The $97^{\text {th }}, 95^{\text {th }}, 75^{\text {th }}, 25^{\text {th }}, 5^{\text {th }}$ and $2.5^{\text {th }}$ percentiles values of NB length at each week of gestation are shown in Table 2.

Table 2: Distribution of NBL according to gestational age as percentiles.

\begin{tabular}{|c|c|c|c|c|c|c|c|c|}
\hline \multirow{2}{*}{ Gestational age (weeks + days) } & \multirow{2}{*}{ n } & \multicolumn{7}{|c|}{ Percentiles (mm) } \\
\hline & & 97.5 & 95 & 75 & 50 & 25 & 5 & 2.5 \\
\hline $11-11+6$ & 58 & 3.76 & 3.5 & 3.2 & 2.85 & 2.57 & 2 & 2 \\
\hline $12-12+6$ & 129 & 4 & 4 & 3.3 & 3.1 & 2.7 & 2.2 & 2.1 \\
\hline $13-13+6$ & 94 & 4.56 & 4.33 & 3.6 & 3.2 & 2.97 & 2.3 & 2.1 \\
\hline
\end{tabular}

Graphical representation of changes in nasal bone length with period of gestation (POG) at $5^{\text {th }}, 50^{\text {th }}$ and $95 \mathrm{rh}$ percentiles are shown in the Figure 2.

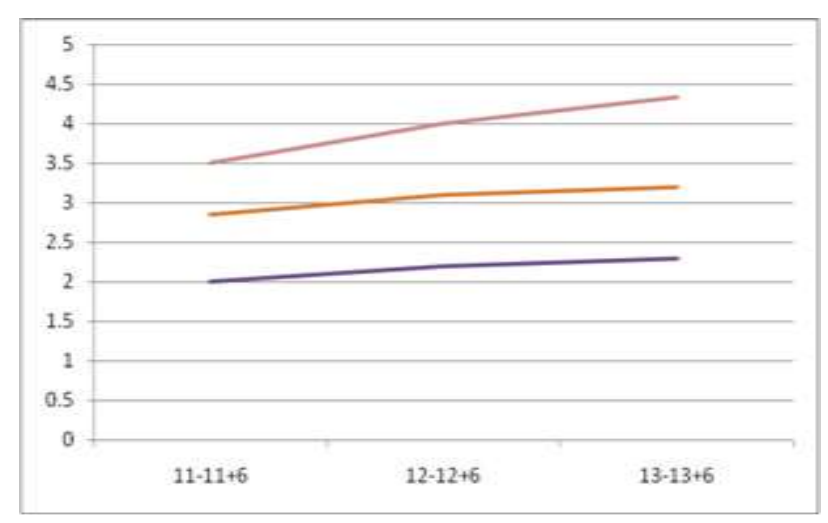

Figure 2: Variation of nasal bone length according to gestational age.

Per week change in POG will result in $0.249 \mathrm{~mm}$ change of NBL. A significant positive correlation was observed, as correlation (Pearson) coefficient is 0.346 with $p$ $<0.001$.

\section{Nasal bone and crown rump length}

Nasal bone length increased with increasing CRL. According to Pearson correlation, the NB length is found to have weak positive correlation with CRL with value of 0.291 . This was statistically significant.

Regression equation of NB length will crown rump length is as shown below:

$\mathrm{NBL}=2.205+0.014 \times \mathrm{CRL}(\mathrm{r}=0.291, \mathrm{p}$ value 0.000$)$

According to Pearson correlation, the NB length has weak positive correlation with period of gestation with value 0.346. Regression equation of NB length with gestational age is as shown below:

$\mathrm{NBL}=-0.050+0.249 \times$ POG $(r=0.346$, value 0.000$)$

Nasal bone length increases by $0.014 \mathrm{~mm}$ per change in CRL. The change is statistically significant, since the $p$ value is less than 0.001 . 


\section{Nasal bone and biparietal diameter and femur length}

Nasal bone length increased linearly with BPD and femur length. NBL is found to have weak positive correlation with BPD with value of 0.286 . The mean BPD/NBL ratio is $6.62(\mathrm{SD}=1.55)$.

Regression equation of NB length with BPD is as shown below:

$\mathrm{NBL}=2.184+0.046 \times \mathrm{BPD}(\mathrm{r}=0.286, \mathrm{p}$ value 0.000$)$

Nasal bone length increases by $0.046 \mathrm{~mm}$ per mm change in BPD. The change is statistically significant since the $p$ value is less than 0.001 .

Nasal bone length is found to have positive correlation with FL with value of 0.369 . The regression of NBL and FL is as shown by the equation below:

$\mathrm{NBL}=2.234+0.095 \times \mathrm{FL}(\mathrm{r}=0.369, \mathrm{p}$ value 0.000$)$

Nasal bone length increases by $0.095 \mathrm{~mm}$ per $\mathrm{mm}$ increase in FL. The change is statistically significant, since the $\mathrm{p}$ value is less than 0.001 .

Regression analysis equation of BPD/NBL ratio with gestational age is given by the formula:

$\mathrm{RBPD}=0.603+0.478 \times \mathrm{POG}$
By this equation, we could see that $\mathrm{BPD} / \mathrm{NBL}$ ratio increases by 0.478 units per week increase of gestation. This was statistically significant. But had weak correlation with gestational age $(0.231$, p value $<0.01)$ by Pearson correlation analysis. By multiple regression analysis, NBL is given by:

$\mathrm{NBL}=1.256+(-0.255 \times \mathrm{RBPD})+(0.080 \times \mathrm{BPD})+$ $(0.186 \times \mathrm{NT})+(0.135 \times \mathrm{POG})$

\section{Prenasal thickness (PT) and gestational age}

Prenasal thickness was measured in 209 patients $(70.13 \%$ ). The mean value is 1.4324 (range, $0 .-3 \mathrm{~mm}$; SD, 0.3908). Mean PT increased with increased gestational age as shown in Table 3.

Table 3: Descriptive measurements of PT according to the gestational age.

\begin{tabular}{|lcccl|}
\begin{tabular}{|l} 
Gestational age \\
(weeks and days)
\end{tabular} & n & $\begin{array}{c}\text { Mean } \\
(\mathrm{mm})\end{array}$ & SD & $\begin{array}{l}\text { Standard } \\
\text { error of } \\
\text { mean }\end{array}$ \\
\hline $11-11+6$ & 39 & 1.345 & 0.3377 & 0.541 \\
\hline $12-12+6$ & 98 & 1.392 & 0.3639 & 0.368 \\
\hline $13-13+6$ & 72 & 1.546 & 0.4352 & 0.513 \\
\hline
\end{tabular}

The $50^{\text {th }}$ percentile value of PT between $11-13+6$ week of gestation were $1.38 \mathrm{~mm}$. The $97^{\text {th }}, 95^{\text {th }}, 75^{\text {th }}, 25^{\text {th }}, 5^{\text {th }}$ and percentiles values of PT at each week of gestation are shown in Table 4.

Table 4: Reference values of PT in percentiles according to the gestational age.

\begin{tabular}{|c|c|c|c|c|c|c|c|c|}
\hline \multirow{2}{*}{$\begin{array}{l}\text { Gestational age } \\
\text { (weeks +days) }\end{array}$} & \multirow[b]{2}{*}{ n } & \multicolumn{7}{|c|}{ Percentile (mm) } \\
\hline & & 97.5 & 95 & 75 & 50 & 25 & 5 & 2.5 \\
\hline $11-11+6$ & 39 & 2.2 & 2 & 1.6 & 1.3 & 1.1 & 1 & 0.6 \\
\hline $12-12+6$ & 98 & 2.243 & 2 & 1.6 & 1.3 & 1.2 & 0.795 & 0.6 \\
\hline $13-13+6$ & 72 & 2.620 & 2.514 & 1.8 & 1.5 . & 1.2 & 1 & 0.948 \\
\hline
\end{tabular}

Prenasal thickness increased linearly with CRL and POG. According to Pearson correlation, the PT has weak positive correlation with POG with value of 0.150 , which is statistically significant at $\mathrm{p}$ value of 0.05 .

Regression equation of PT with gestational age is as shown below:

$\mathrm{PT}=0.430+0.08 \times$ POG $(\mathrm{r}=0.15, \mathrm{p}$ value $=0.028)$

Per week change in POG will result in $0.08 \mathrm{~mm}$ change of NT.

\section{Prenasal thickness and crown rump length}

Prenasal thickness was found to increase with increase in CRL. A positive correlation was observed between PT and CRL, as correlation (Pearson) coefficient is 0.160 . This is statistically significant at $p$ value of 0.05 .

By regression analysis,

$\mathrm{PT}=1.081+0.006 \times \mathrm{CRL}(\mathrm{r}=0.16, \mathrm{p}$ value $=0.02)$

On multiple stepwise regressions, PT is given by the following equation:

$\mathrm{PT}=1.077+0.04 \times$ FL $(\mathrm{r}=0.217, \mathrm{p}$ value $=0.002)$

\section{DISCUSSION}

Nomogram is most essential to differentiate normal from abnormal parameter in index population. Assessment of NB merely by presence or absence is a subjective 
phenomenon. Measurement of NB length is an objective approach, and leads to setting of nomogram, thereby categorizing NB hypoplasia. Hence, this study is an attempt to set nomogram of nasal bone between 11-14 week gestations in Indian population.

In this study population, the age of pregnant women ranged from 20 to 39 years (mean, 28 years; SD, 3.98). Although, it is a known fact that risk of aneuploidy increases with maternal age, $70 \%$ of Down syndrome babies are born to young mothers aged less than 35 years. The age related risk for trisomy 21 at 12 weeks for 20 and 39 years are $1: 1068$ and 1:89, respectively. ${ }^{8}$

\section{Nasal bone measurements}

NB can be displayed by ultrasonagraphy after $10^{\text {th }}$ gestational week. ${ }^{4}$ In present study, measurements were taken between 11 weeks and 13 weeks and 6 days. Lowest NBL measurement recorded in this study was $1.6 \mathrm{~mm}$. It was put forth that these bones could be measured beginning from $0.8 \mathrm{~mm}$ in $10^{\text {th }}$ week, it may be evaluated shorter or longer than normal and even it may be supposed as non-existed, especially in early gestation.

The mean period of gestation in this study at the time of sonographic evaluation was 12 weeks and 4 days (SD, $0.7702)$. 129 out of 281 patients $(45.9 \%)$ of this study were clustered at 12 weeks of gestation. In various studies, the $50^{\text {th }}$ percentile distribution at $12^{\text {th }}$ week shows a wide range of variation. The smallest measurement of $1.5 \mathrm{~mm}$ was seen by Cicero et al and largest was $3.1 \mathrm{~mm}$ by present study. The value at $12^{\text {th }}$ week in present study is close to values given by Sonek et al and Orlandi et al, series. $^{6,9}$

Similar with other studies, NBL increased linearly with gestational age as shown in table 15. Mean NB length was $3.0727 \mathrm{~mm}(\mathrm{SD}=0.53)$. As compared to other studies, mean values in each week of this study are higher, but closely matching Ozer et al, study and far from Cusick et al, study. ${ }^{10,11}$

We suspect that these highly different values among populations are not solely explained by maternal ethnicity, but are also due to variation in technique such as including or excluding the relatively hypoechogenic ends of NB. ${ }^{12}$

As NB increased linearly with CRL and gestational age in this study as in other studies. Increments of NB length with CRL showed wide variability in different studies as shown in Table 5.

In this study, nasal bone increased by $0.014 \mathrm{~mm}$ per $\mathrm{mm}$ increase in CRL which was lesser than that observed in other population. This could be due to difference in population,sample size and techniques of measurement.
Table 5: Relationship of nasal bone length with CRL.

\begin{tabular}{|llll|}
\hline Author & N & $\begin{array}{l}\text { Place of } \\
\text { study }\end{array}$ & $\begin{array}{l}\text { Regression vale } \\
\text { of CRL with } \\
\text { NBL (mm) }\end{array}$ \\
\hline $\begin{array}{l}\text { Cicero et al, } \\
2002^{4}\end{array}$ & 955 & UK & 0.019 \\
\hline $\begin{array}{l}\text { Moon et al, } \\
2006^{5}\end{array}$ & 823 & Korea & 0.022 \\
\hline $\begin{array}{l}\text { Chen et al, } \\
2006^{7}\end{array}$ & 2,169 & Hong Kong & 0.0374 \\
\hline $\begin{array}{l}\text { Sahota et al, } \\
2009^{13}\end{array}$ & 7,517 & Hong Kong & 0.0186 \\
\hline $\begin{array}{l}\text { Casasbuenas } \\
\text { et al, 2009 }\end{array}$ & 1,040 & $\begin{array}{l}\text { Chile (Latin } \\
\text { America) }\end{array}$ & 0.02 \\
\hline $\begin{array}{l}\text { Ozer et al, } \\
\text { 2009 }\end{array}$ & 415 & Turkey & 0.043 \\
\hline $\begin{array}{l}\text { Present } \\
\text { study }\end{array}$ & 281 & India & 0.014 \\
\hline
\end{tabular}

\section{Nasal bone length with biparieter diameter and femur length}

In present study, the NB length had statistically significant linear relationship with BPD and FL ( $p<0.001)$ Table 6. But, the correlation is found to be weak. FL and BPD parameters demonstrated the highest and lowest correlation with the NB length, respectively.

Table 6: Relation of nasal bone length with biparietal diameter and femur length.

\begin{tabular}{|lllll|}
\hline Study & N & $\begin{array}{l}\text { Place } \\
\text { of } \\
\text { study }\end{array}$ & $\begin{array}{l}\text { Regression } \\
\text { value of } \\
\text { NBL with } \\
\text { BPD (MM) }\end{array}$ & $\begin{array}{l}\text { Regression } \\
\text { value of } \\
\text { NBL with } \\
\text { FL (mm) }\end{array}$ \\
\hline $\begin{array}{l}\text { Yayla et } \\
\text { al, 2006 }\end{array}$ & 276 & Turkey & 0.15 & 0.16 \\
\hline $\begin{array}{l}\text { Sivri et } \\
\text { al, 2006 }\end{array}$ & 373 & Turkey & 0.056 & 0.075 \\
\hline $\begin{array}{l}\text { Present } \\
\text { study }\end{array}$ & 281 & India & 0.046 & 0.095 \\
\hline
\end{tabular}

Studies have shown that NB shows a linear growth characteristic in parallel to growth of other bones in second and third trimesters also.

BPD/NBL ratio in this study is found to be very low compared with that of previous studies as shown in Table 7. This difference may be due to difference in gestational period as other studies are exclusively done in second trimester.

Since, in literature reference studies were done only in second trimester. The application of BPD/NBL ratio in this population even its utilization in first trimester needs further studies. Further, to set particular ratio value studies are needed to compare the results in euploid and 
aneuploid groups. This could not be commented by this study as this is one armed study.

Table 7: Biparietal diameter/nasal bone length ratio.

\begin{tabular}{|llll|l|}
\hline Author & $\mathbf{n}$ & $\begin{array}{l}\text { POG } \\
\text { (weeks) }\end{array}$ & $\begin{array}{l}\text { Place } \\
\text { of } \\
\text { study }\end{array}$ & $\begin{array}{l}\text { BPD/NBL } \\
\text { ratio in } \\
\text { euploid } \\
\text { fetuses }\end{array}$ \\
\hline $\begin{array}{l}\text { Bromley et } \\
\text { al, 2002 }\end{array}$ & 239 & $15-20$ & Boston & $8.1 \pm 1.4$ \\
\hline $\begin{array}{l}\text { Kanagawa } \\
\text { et al, 2006 }\end{array}$ & 356 & $15-25$ & Japan & 9.01 (median) \\
\hline $\begin{array}{l}\text { Present } \\
\text { study }\end{array}$ & 281 & $11-14$ & India & 6.62 \\
\hline
\end{tabular}

The mid-sagittal view of the fetal face is defined by the presence of the echogenic tip the nose and rectangular shape of the palate anteriorly, the translucent diencephalon in the center and the nuchal membrane posteriorly. ${ }^{19}$ Deviations from the exact midline plane result in non visualization of the tip of the nose and visibility of the zygomatic process of the maxilla and subsequently wrong assessment.

In literature, obtaining a proper profile for NB measurement is over $90 \%$ in all studies, with exception of FASTER trial $(75.9 \%) .{ }^{20}$ In this study, we measured NB length using the standard recommendations laid by
American fetal medicine foundation unit. We were able to get proper profile of NB length in 281 patients (94.34\%) respectively. The NB length increases with advancing gestational age. Therefore, the false positive rate decreases with gestation. ${ }^{6}$ The visualization of nasal bone also improves with gestation. Like in this study, success rate of visualization at 11 weeks was $81 \%$ compared with $97-99 \%$ at later gestational weeks. However in FASTER trial, failure to obtain adequate NB imaging was significantly more likely at 10 weeks of gestation, compared with that at 11 weeks of gestation.

FASTER trial, which is one of the largest series of NB assessment, could not obtain adequate images in 1,523 cases $(24.1 \%)$. $^{20}$ Demonstrating the absence of a very small structure is even more difficult than detecting its presence, because it can be difficult to know for certain whether the nasal bones are absent or whether the images are simply suboptimal. Therefore, application of NB sonography will be limited at early gestational ages when the nasal bones are particularly small.

\section{Nasal bone length variation with ethnicity}

It has been shown in various studies that NB length varies with ethnicity table 8 . Definition of normal NB length varies with population. It is not only the length, but the prevalence of absent NB in euploid fetuses also varies in different groups.

Table 8: Distribution of nasal bone in different ethnic groups.

\begin{tabular}{|c|c|c|c|c|c|c|c|c|c|c|c|}
\hline \multirow[b]{2}{*}{ Author } & \multirow[b]{2}{*}{$\mathbf{N}$} & \multirow{2}{*}{ Study population } & \multicolumn{3}{|c|}{$11-11+6$ week } & \multicolumn{2}{|c|}{ 12-12+6 week } & \multicolumn{3}{|c|}{ 13-13+6 week } & \multirow[b]{2}{*}{5} \\
\hline & & & 95 & 50 & 5 & 95 & 50 & 5 & 95 & 50 & \\
\hline Sonek et al, $2003^{6}$ & 115 & $\begin{array}{l}\text { Africo- } \\
\text { American+Caucasiant } \\
(19+96)\end{array}$ & 3.3 & & & 4.2 & & & 4.6 & & \\
\hline Moon et al, $2006^{5}$ & 823 & Korean & 1.9 & 1.5 & 1.2 & 2.1 & 1.7 & 1.4 & 2.3 & 1.9 & 1.6 \\
\hline Chen et al, $2008^{7}$ & 2,169 & Chinese & - & - & - & 2.8 & 2.2 & 1.7 & 3.2 & & 2 \\
\hline Cossi et al, $2008^{21}$ & 171 & Brazilian & 2 & 1.6 & 1.1 & 2.5 & 2 & 1.4 & 3.0 & 2.4 & 1.7 \\
\hline Casasbuenas et al, $2009^{14}$ & 1,040 & Latin American & 1.8 & 1.5 & 1.0 & 2.2 & 1.7 & 1.2 & 2.4 & 1.9 & 1.4 \\
\hline Present study & 281 & Indian & 3.5 & 2.85 & 2 & 4 & 3.1 & 2.2 & 4.33 & 3.2 & 2.3 \\
\hline
\end{tabular}

Nasal bone length of this study is longer than that observed in Chinese, Brazilian and Korean fetuses. However, $95^{\text {th }}$ percentile of present study fetuses is less, but comparable to that observed by Sonek et al in mixed population.

Mean NB length at particular gestation and CRL was compared with other ethnic groups in table below. Nasal bone length of present study is comparable to white population. This was contrary to the findings of Colloda et al, as Asian fetuses had short NB in his study.
Table 9: Nasal bone length as to CRL in various ethnic groups.

\begin{tabular}{|c|c|c|c|c|}
\hline $\begin{array}{l}\text { Ethnic } \\
\text { group }\end{array}$ & n & $\begin{array}{l}\text { POG } \\
(\text { week }) \\
(\text { mean } \pm \text { SD })\end{array}$ & $\begin{array}{c}\text { CRL }(\mathrm{mm}) \\
(\mathrm{mean} \pm \mathrm{SD})\end{array}$ & $\begin{array}{l}\text { NB length } \\
(\mathrm{mm}) \\
(\mathrm{mean} \pm \mathrm{SD})\end{array}$ \\
\hline Hispanic & 93 & $12.3 \pm 1.4$ & $60.2 \pm 14$ & $2.5 \pm 0.6$ \\
\hline White & 51 & $12.4 \pm 1$ & $61 \pm 14$ & $2.9 \pm 0.7$ \\
\hline Black & 27 & $12.3 \pm 1.4$ & $58.6 \pm 15$ & $2.5 \pm 0.6$ \\
\hline Chinese & 30 & $12.5 \pm 0.6$ & $62.4 \pm 8.8$ & $2.2 \pm 0.4$ \\
\hline $\begin{array}{l}\text { Present } \\
\text { study }\end{array}$ & 281 & $12.5 \pm 0.77$ & $60.8 \pm 11$ & $3.07 \pm 0.53$ \\
\hline
\end{tabular}


The present study results cannot be compared with other similar studies in different populations. Because, the different results are not explainable only by ethnicity as there are many technical or methodologic factors confounds the results. Off course, measurement of NB accurately challenge ones sonographic skills. The variations in nasal bone were found to be statistically significant in studies and suggested corrections for maternal ethnicity for utilizing the fetal NB length in the screening for trisomy 21 in first trimester. ${ }^{22}$ However, its implication in clinical practice is yet to come.

\section{CONCLUSION}

Nasal bone assessment in early pregnancy is feasible and can be obtained along with nuchal translucency as both are obtained in the midsagittal plane. Our results of NB measurements support the existence of ethnic variability in nasal bone length. Since this is a small pilot study in Indian population, further prospective studies in larger population are needed to evaluate the results. This is the preliminary study to establish the relation of $\mathrm{BPD} / \mathrm{NBL}$ ratio in 11-14 week as the reference studies were exclusively of second trimester. To implement BPD/NBL ratio in this population, further studies are needed in this direction. This data can provide a reference for future studies aiming to evaluate the role of NB hypoplasia in the first trimester sonographic screening of trisomy 21 in Indian population.

\section{Funding: No funding sources} Conflict of interest: None declared

Ethical approval: The study was approved by the Institutional Ethics Committee

\section{REFERENCES}

1. Chen X, Chang Y, Cui HY, Ren CC, Yu BY. Study on several ultrasound markers combined maternal serum biochemical markers to screen fetal chromosomal aneuploidy at 11 to $13(+) 6$ weeks of gestation. 2013 Nov;48(11):815-8.

2. Masihi S, Mojgan B, Razieh M, Hashemi M. Assessment of nasal bone in first trimester screening for chromosomal abnormalities in Khuzestan, Iran J Reprod Med. 2014;12(5):321-6.

3. Collado F, Bombard A, Li V. Ethnic variation of fetal nasal bone length between 11-14 weeks, gestation. Prenat Diagn. 2005;25:690-2.

4. Cicero S, Bindra R, Rembouskos G, Tripsanas C, Nicolaides KH. Fetal nasal bone length in chromosomally normal and abnormal fetuses at 1114 weeks of gestation. J Matern Fetal Neonatal Med. 2002;11(6):400-2.

5. Moon MH, Cho Jy, lee YM. Nasal bone length at 1114 weeks of pregnancy in the Korean Population. Prenat Diagn. 2006;26:524-7.

6. Sonek JD, Mckenna D, Webb D, Croom C, Nicolaides K. Nasal bone length throughout gestation; normal ranges based on 3537 fetal ultrasound measurements. Ultrasound Obstet Gynecol. 2003;21:152-5.

7. Chen M, Lee C, Tang R. First-trimester examination of fetal nasal bone. Prenat Diagn. 2006;26:703-6.

8. Snijders RJ, Noble P, Sebire N, Souka A. U.K multicentric project on assessment of risk of trisomy 21 by maternal age and fetal nuchal transiucency thickness at 10-14 week gestation. Fetal medicine foundation first trimester screening group, Lancet. 1998;352:343-6.

9. Orlandi F, Bilardo CM, Campogrande M, Krantz D, Hallahan Td, Rossi C. Measurement of nasal bone length at 11-14 weeks of pregnancy and its potential role in Down syndrome risk assessment. Ultrasound n Obstet Gynecol. 2003;22:36-9.

10. Ozer A. Oaksit A, Kanat-Pektas M, Oer S. First trimester examination of fetal nasal bone in the Turkish population. Jounal of Obstetrics and Gynaccology Research. 2010;36(4):739-44.

11. Cusick W, Provenzano J, Christopher. A. Sullivan, Francene M. Gallousis, John F. Rodis. Rodis. Fetal Nasal Bone Length in Euploid and Aneuploid Fetuses between 11 and 20 weeks Gestation; A Prospective study. J Ultrasound Med. 2004;23:132733.

12. Sonek JD, Cicero S, Neiger R, Nicolaides K. Nasal bone assessment in prenatal screening for trisomy 21. Am J Obstet Gynecol. 2006;195(5):1219-30.

13. Sahota DS, Leung TY, Chan LW, Law LW, Fung TY. First-trimester fetal nasal none length in an ethnic Chinese population. Ultrasond in Obstet Gynecol. 2009;34(1):33-7.

14. Cassasbuenas A, Amy E, Wong, Waldo. First trimester nasal bone length in a normal Latin America population. Prenat Diagn. 2009;29:108-12.

15. Yayla M, Guynumer G, Uysal O. Fetal nasal bone length nomogram. Perinatal Journal. 2006;14(2):7782.

16. Sivri D, Dane C, Dane B, Çetin A, Yayla M. 1113+6 gebelik haftas $\gg$ ndaki fetüslerde nazal kemik uzunluk nomogram». Perinatoloji Dergisi. 2006;14:122-8.

17. Bromley B, Lieberman E, Shipp TD, Benacerraf BR. Fetal nose bone length: a marker for Down syndrome in the second trimester. $\mathbf{J}$ ultrasound Med. 2002;21:1387-94.

18. Kanagawa T, Fukuda H, Kinugasa $Y$, Son $M$, Shimoya K. Mid-second trimester measurement of fetal NB length in the Japanese population. Journal of Obstetrics and Gynaecology Research. 2006;32(4):403-7.

19. Plasencia W, Dagklis T, Sotiriadis A, Borenstein M, Nicolaides KH. Frontomaxillary facial angle at $11+0$ to $13+6$ weeks' gestation reproducibility of measurements. Ultrasond Obstet Gynecol. 2007;29:18-21.

20. Malone FD, Ball RH, Nyberg DA, Comstock CH, Saade G, Berkowitz RL, et al. Faster Research consortium. First trimester nasal bone evaluation for 
ancuploidy in the general population. Obstet Gynecol. 2004;104:1222-8.

21. Cossi PS, Araujo Junior E, Bussamra LCS, Guimaraes Filho HA, Nardozza LMM, Moron AF. Measurement of fetal nasal bone length in the period between 11 and 15 gestational weeks in a Brazilian population: a preliminary study. Radiol Bras. 2008;41(3):155-8.
22. Prefumo F, sairam S, Bhide A. Maternal ethnic origin and fetal nasal bones at 11-14 weeks of gestation. BJOG. 2004;11:109-12.

Cite this article as: Prabha R, Kumar S, Kumar M. Nomogram of nasal bone length at 11-14 week of gestation in Indian women and their follow up till delivery. Int J Reprod Contracept Obstet Gynecol 2016;5:3704-11. 